\title{
Atividades com Comunicação \& Educação Ano XII - n. 1
}

Ruth Ribas Itacarambi

Doutora pela Faculdade de Educação da USP.

Educadora e pesquisadora do CAEM - Centro de Aperfeiçoamento do Ensino da Matemática do IME-USP. Professora da FOC - Faculdade Osvaldo Cruz. Membro da Equipe SiteEducacional.

E-mail: ruthri@uol.com.br

Todas as pessoas nascem livres e iguais em dignidade e direitos.

São dotadas de razão e consciência e devem agir em relação umas às outras com espírito de fraternidade

(Declaração dos Direitos Humanos - ONU).

A Declaração Universal dos Direitos Humanos apresenta um ideal comum a ser atingido por todos os seres humanos em seus países, com o objetivo de que cada cidadão esforce-se, mediante o ensino e a educação, por promover o respeito aos direitos apresentados nessa declaração de liberdade. Observa-se que o documento faz distinção entre ensino e educação. A reflexão sobre este tema tem como ponto de partida os artigos: Declaração Universal dos Direitos Humanos, o documento mais importante elaborado pelo homem, em entrevista com Maria Luiza Marcílio, A utopia brasileira da mídia cidadã, de José Marques de Melo e o depoimento de Cyro Del Nero, Tornei-me o homo faber por excelência.

A Organização dos Estados Ibero-Americanos para a Educação, a Ciência e a Cultura (OEI) - ou "Organización de Estados Ibero-americanos para la Educación, la Ciencia y la Cultura" - é um organismo internacional de caráter governamental para a cooperação entre os países ibero-americanos nos campos da educação, da ciência, da tecnologia e da cultura no contexto do desenvolvimento integral. Apresenta entre os seus fins gerais e específicos o seguinte: "Contribuir a fortalecer o conhecimento, a compreensão mútua, a integração, a solidariedade e a paz entre os povos ibero-americanos através da educação, da ciência, da tecnologia da cultura" .

Nesse documento, a educação é apresentada como uma alternativa à construção da paz, pois tenciona preparar o ser humano para o exercício responsável da liberdade, da solidariedade, da defesa dos direitos humanos e das mudanças que possibilitem uma sociedade mais justa. A educação na perspectiva do desenvolvimento a serviço do ser humano relaciona a ciência, a tecnologia e a cultura.

1. OIE - <http://www.direitoshumanos.usp.br/>. 
Esta temática está presente nos artigos Comunicação e memória em tempos de repressão: uma análise interdisciplinar de "Memórias do cárcere" e "Primavera con una esquina rota", de Adriana Coelho Florent, e $O$ discurso hegemônico de Veja $e$ a construção da imagem do pobre, de Baccega e Azevedo.

A Pedagogia é objeto de reflexão no artigo: As histórias em quadrinhos para a formação de leitores ecléticos: algumas reflexões com base em depoimentos de universitários, de Bari e Vergueiro. Para os autores, a Pedagogia, num contexto de interdisciplinaridade provocado pelas mídias, tem como cenário a crise internacional da leitura e da cidadania, em que grande parte das ações pedagógicas em relação à mídia não passa de tarefas impostas pela política pública, sem vínculo ou compromisso ético com os envolvidos, tratados como receptores da cultura das elites. Complementando esta questão temos o artigo Os espaços de leitura, de Angela Maria Barreto, que retoma a concepção de sociedade contemporânea em constante mudança: o trânsito entre as palavras ditas e escritas, as formas de se relacionar com o outro, os gestos que expressam as diversas experiências e auxiliam na comunicação e os lugares da comunicação e da leitura.

Nesta sociedade das mídias, o artigo A televisão e o vídeo em sala de aula: uma experiência realizada com professores e alunos de História, de Maria Elizabete Souza Couto, traz uma análise das modalidades de utilização da televisão e do vídeo na educação, a relação entre os conteúdos dos programas e os das áreas de ensino, como de História, e até que ponto esses conteúdos permitem preparar os jovens para os desafios socioculturais pretendidos no documento da OIE.

$\mathrm{O}$ artigo Telenovela e realidade social: algumas possibilidades dialógicas, de Motter e Jakubaszko, por opção metodológica dos autores distingue na telenovela duas dimensões: a melodramática e a social. Consideram a dimensão social como o traço que mais diferencia as nossas produções das melodramáticas, além de apresentarem um caráter pedagógico, pois "antes de ser uma história, a novela é uma instrução, um ensinamento, uma saber"'.

As três atividades com os artigos desta edição da revista têm como propósito apresentar sugestões para serem desenvolvidas em sala de aula, discutindo a questão dos Direitos Humanos, o papel da educomunicação como alternativa para a construção da democracia e as mídias na sala de aula.

2. LARROSA, J. A novela pedagógica e a pedagogização da novela. In: LARROSA, J. Pedagogia profana: danças, piruetas e mascaradas. Belo Horizonte: Autêntica, 1999. p. 118.

\section{PRIMEIRA ATIVIDADE}

\section{Os direitos humanos e a educação}

A atividade objetiva discutir como a educação, o conhecimento científico e tecnológico e a cultura contribuem para a compreensão mútua, a integração, a solidariedade e a paz entre os diferentes segmentos sociais e países. O artigo Declaração Universal dos Direitos Humanos, o documento mais importante elaborado pelo homem é o apoio para esta atividade, pois na entrevista a professora relata sua 
experiência na área dos Direitos Humanos, como, por exemplo, na Febem de São Paulo, onde pôde conferir a falta de políticas públicas de educação para os jovens que ali se encontram. Conta sobre seu trabalho na comissão de Direitos Humanos da USP com a criação de uma Biblioteca Virtual para disponibilizar informação ao público.

A atividade que propomos pode ser trabalhada no Ensino Básico e nos cursos de formação de profissionais de diferentes áreas do conhecimento. É preciso, apenas, estar atento aos níveis de exigência para cada grupo e organizar-se na seguinte seqüência didática:

1) A leitura individual da entrevista, registrando as considerações da professora sobre:

- sua experiência e dificuldades na Febem;

- a criação e funcionamento da Comissão dos Direitos Humanos; e

- a criação da Biblioteca Virtual.

2) Fazer uma síntese das considerações para cada item, em sala de aula, dando destaque à Biblioteca Virtual como meio de informação sobre a Declaração dos Direitos Humanos dos diferentes órgãos.

3) Solicitar que os alunos consultem o site da Biblioteca Virtual e, neste, a página dos Direitos Humanos e façam uma síntese dos organismos que estão registrados e seus princípios.

Em grupo, os alunos podem analisar como cada órgão apresenta a concepção de ensino e de educação em seus princípios e conteúdos.

Selecionar discursos de campanhas eleitorais que tratem da educação e dos jovens e solicitar que os alunos leiam e comparem com os conteúdos propostos nesses organismos.

No desenvolvimento do trabalho é importante lembrar o papel modernizador das mídias, principalmente em sociedades que mantêm contingente humano à margem do desenvolvimento econômico. Este tema é tratado no artigo A utopia brasileira da mídia cidadã, que lembra a existência de sistemas midiáticos, um massivo e outro popular. A questão é como os direitos humanos são apresentados nesses sistemas.

O artigo Tornei-me o homo faber por excelência dá continuidade à discussão sobre os direitos humanos e o papel da educação, trazendo como cenário as expressões culturais a partir do depoimento de Cyro Del Nero e sua presença na escola.

O artigo faz uma retrospectiva da formação profissional do autor no teatro, na moda, no cinema, na televisão e no movimento popular carnaval.

1) Solicitar que os alunos façam uma investigação em sua cidade e/ou comunidade sobre expressões culturais próprias de seu grupo de referência, tais como jornal do bairro, teatro, grafitagem, bandas, músicas, entre outras.

2) Analisar os conteúdos dessas expressões tendo como referência os direitos humanos e os princípios apontados nos órgãos pesquisados, em particular o papel da escola na educação. 
comunicação \& educação • Ano XII • Número 1 • jan/abr 2007

3) Fechar a atividade com a síntese das análises e com a leitura do item A Experiência com a Educação, no depoimento de Nero.

\section{SEGUNDA ATIVIDADE}

\section{A educomunicação como alternativa para a construção da democracia}

O objetivo da atividade é chamar a atenção dos profissionais da educação sobre histórias que contam a vivência de prisioneiros políticos em diferentes tempos e que mostram a violação dos direitos humanos individuais, justificando-a em benefício da coletividade. Em histórias como as do artigo Comunicação e memória em tempos de repressão: uma análise interdisciplinar de "Memórias do cárcere" e "Primavera con una esquina rota", nas quais a liberdade é suprimida por meio da violência, a criação literária exerce a função de ressuscitar o passado através de um trabalho de rememoração crítica.

A atividade que propomos tem a seguinte seqüência didática:

1) Solicitar que os alunos leiam o artigo, identifiquem o período histórico tratado nas duas obras literárias citadas e registrem as características de cada um desses momentos políticos.

2) Escolher um capítulo do livro de Graciliano Ramos, Memórias do cárcere - que, se possível, deve ser lido inteiro -, solicitar que os alunos leiamno individualmente e depois, em grupo, discutam o ambiente em que se passa a história, respondendo às questões:

- Como é descrito o tratamento dado aos prisioneiros?

- Os ideais da Declaração dos Direitos humanos são respeitados? Por quê?

- Você lembra outra história recente que relate o tratamento dado aos prisioneiros políticos?

3) Fazer a síntese das principais considerações dos grupos.

4) Selecionar algumas matérias de jornais e/ou revistas que tratem da invasão do Iraque pelos americanos e dêem as justificativas dessa invasão. Analisar os fatos e relacioná-los com os ideais dos Direitos Humanos.

$\mathrm{O}$ artigo $O$ discurso hegemônico de Veja $e$ a construção da imagem do pobre pode subsidiar o item 4 da atividade, uma vez que dá continuidade à reflexão e traz como contribuição a necessidade de se fazer uma análise crítica das informações veiculadas nos diferentes meios de comunicação.

\section{TERCEIRA ATIVIDADE}

\section{As mídias na sala de aula}

$\mathrm{O}$ artigo As histórias em quadrinhos para a formação de leitores ecléticos: algumas reflexões com base em depoimentos de universitários discute a função social da leitura 
sob a ótica da apropriação individual e coletiva da cultura, e mostra que as formas de fazer da Educação adquirem novos significados com a Comunicação e outras áreas baseadas nas relações sociais e na valorização do ser humano, bem como na afetividade e na mediação participativa e interativa da cultura.

Esta atividade é dirigida a dois públicos complementares: alunos da Escola Básica e alunos da graduação, em particular Pedagogia e Letras.

1) Conversar com os alunos sobre suas leituras de revistas em quadrinhos, seus títulos preferidos e em que momento começaram a interessar-se por esse tipo de publicação.

2) Solicitar que os alunos façam uma redação com o tema "Minha vida em quadrinhos".

3) Ler as redações e classificá-las de acordo com os momentos em que ocorreram os primeiros contatos dos alunos com os quadrinhos; para isso, utilizar a classificação proposta pela autora no item Primeiro contato com as histórias em quadrinhos.

4) Apresentar para os alunos a classificação e solicitar que leiam o artigo e comparem a classificação da autora com a de sua sala de aula.

5) Analisar com os alunos a desaprovação da família e da comunidade em relação às histórias em quadrinhos, assim como a visão depreciativa presente na comunidade escolar.

6) $\mathrm{O}$ artigo A televisão e o vídeo em sala de aula: uma experiência realizada com professores e alunos de História apresenta duas linguagens da comunicação - a televisão e o vídeo - que, apesar de muitas vezes serem ignoradas pela escola, são articuladoras de aprendizagens, como as histórias em quadrinhos.

Esta atividade é voltada para o planejamento do trabalho dos professores do Ensino Básico e, em particular, dos professores de História.

1) Ler o artigo e identificar a relação entre os conteúdos propostos por série e os conteúdos dos filmes.

2) Relacionar os conteúdos de sua programação que poderiam ser abordados, utilizando-se de filmes em vídeo.

3) Pesquisar no catálogo da TVEscola títulos pertinentes para ser utilizados em sala de aula.

Lembrar que os filmes selecionados precisam ter curta duração, daí a importância da escolha de documentários, que oferecem um número restrito de idéias ou mesmo uma idéia central.

A seleção de imagens também pode ser feita por meio da gravação de episódios de telenovelas, pois, segundo o artigo Telenovela e realidade social: algumas possibilidades dialógicas, elas têm tratado de temas sociais. O professor poderá pesquisar as diferentes problemáticas sociais abordadas nas telenovelas, e citamos algumas que poderão ser norteadoras: a questão da inclusão social, da AIDS e da pobreza, presente na novela mais recente da rede Globo, Páginas da Vida; do preconceito racial em Escrava Isaura; do comércio de crianças e da cultura popular - carnaval -, em Senhora do Destino e outras. 
Resumo: As três atividades com os artigos desta edição da revista têm como propósito apresentar sugestões para serem desenvolvidas em sala de aula, discutindo a questão dos Direitos Humanos, o papel da educomunicação como alternativa para a construção da democracia e as mídias na sala de aula.

Palavras-chave: direitos humanos, educomunicação, democracia, mídia e educação.
Abstract: The three activities with this issue's articles are suggestions to be developed in classroom, discussing the issue of Human Rights, the role of Educommunication as an alternative way to the construction of democracy, and media in classroom.

Keywords: Human Rights, educommunication, democracy, media and education. 